\title{
Representation of Numerical Data by Some Special Mathematical Curves
}

\author{
Dhritikesh Chakrabarty \\ Department of Statistics, Handique Girls' College, Guwahati, Assam, India, \\ dhritikesh.c@rediffmail.com,dhritikeshchakrabarty@gmail.com
}

\begin{abstract}
It is be possible to represent a set of numerical data on a pair of variables by special mathematical curves (other than polynomial curve) besides the representation of said set of numerical data by polynomial curve for which several methods have already been developed. Recently, some studies have been made on mathematical representation of numerical data on a pair of variables by some special mathematical curves (other than polynomial curve) namely exponential curve (both simple \& modified), Pearl \& Reed curve and Makeham's curve. Methods have been developed for representing numerical data by these curves. This paper has been prepared for brief description of the methods for representing numerical data on a pair of variables by these three special curves with numerical examples in order to show the applications of the methods to numerical data.
\end{abstract}

Key words: Pair of variables; special curve; numerical data; method of representation.

\section{Introduction}

Mathematical representation of numerical data plays significant role in many problems in research and investigation. There exist statistical methods for representing numerical data by mathematical curve. However representations by these methods are not accurate but approximate. Recently, some studies have been made on accurate mathematical representation of numerical data by pol Chakrabarty ynomial curve [Chakrabarty , 2016a ; Chakrabarty krabarty 2016b ; Chakrabarty 2016c ; Chakrabarty 2016d ; Chakrabarty 2016e; Chakrabarty 2017a; Chakrabarty 2017b ;Das \& Chakrabarty 2016a ; Das \& 
Chakrabarty 2016b ; Das \& Chakrabarty 2016c ; Das \& Chakrabarty 2016d; Das \& Chakrabarty 2016e ;Das \& Chakrabarty 2016f ; Das \& Chakrabarty 2017a ; Das \& Chakrabarty 2017b]. Some formulae have been derived by them for representation of numerical data by polynomial curve [Das \& Chakrabarty, 2016a - 2016f ]. They have also derived the first formula [Das \& Chakrabarty, 2016a] from Lagrange's Interpolation equation [Echols ,1893; Corliss, 1938 ; Hummel, 1947; Traub, 1964 ; Jardan, 1965; Quadling, 1966 ; Mills, 1977 ; Kendall, 1989 ; Vertesi, 1990 , Kincard \& Ward, 1991 ; Revers \& Michael , 2000 ; Endre \& David, 2003 ; Jan, 2004 ; Nasrin et al., 2010]. The second formula [Das \& Chakrabartyl, 2016b] has been derived from Newton's Divided Difference Interpolation Formula [Herbert, 1962 ; Whittaker \& Robinson 1967a , 1967b ; De Boor et al., 2003.]. The third one [Das \& Chakrabarty, 2016c] has been derived from Newton's Forward Interpolation formula [Erdos \& Turan, 1938 ; Whittaker \& Robinson, 1967a ; Nasrin, 2010 et al] and the fourth one [Das \& Chakrabarty 2016d] has been derived from Newton's Backwards Interpolation formula [Erdos \& Turan, 1938 ; Hummel, 1947 ; Jardan ,1965 ; Whittaker \& Robinson, 1967a ; Kendall, 1989 ; Kincard \& Ward, 1991 ; Endre \& David, 2003 ; Jan et al., 2004]. Later on one method has been constructed by Chakrabarty 2016a , 2016b , 2016c for representing a given set of numerical data on a pair of variables by a suitable polynomial. The method based on two numerical operations namely finite difference operation and ratio operation [Gertrude, 1954 ; Herbert, 1962 ; Jordan, 1965 ; Dokken \& Lyche 1979 ; Fred, 1979 ; Jeffreys \& Jeffreys, 1988 ; Lee, 1989 ; Chwaiger, 1994 ; De Boor, 2003 ; Endre \& David, 2003 ; Floater et al., 2003]. In another study, three methods have been composed by Das \& Chakrabarty [2016e ; 2016f ; 2017a] for the same purpose. The two methods are based on the inversion of a square matrix. The first one is based on matrix inversion from Cayley-Hamilton theorem [Cayley, 1858 , 1889 ; Hamilton et al., 1853 ; 1862 ; 1864a ; 1864b.] while the second \& the third ones are on matrix inversion by elementary row transformation $\&$ elementary column transformation of matrix [Cayley et al., 1858 , 1889 ; Hamilton et al., 1889] respectively.

It is be possible to represent the numerical data on a pair of variables by special mathematical curves other than polynomial curve besides the representation of said numerical data by polynomial curve for which several methods have already been developed. Recently, some studies have been made on mathematical representation of numerical data on a pair of variables by some special mathematical curves other than polynomial curve namely exponential curve (both simple \& modified) [Abramowitz \& Stegun, 1972; Beyer, 1987 ; Krantz ,1999] , Pearl \& Reed curve [Gershenfeld, 1999 ; Jannedy et al., 2003] and 
Makeham curve [Makeham , 1860; Kenney \& Keeping, 1962 ; Makeham, 1874]. Methods have been developed for representing numerical data by these curves. This paper has been prepared for brief description of the methods for representing numerical data on a pair of variables by these three special curves with numerical examples in order to show the applications of the methods to numerical data.

\section{Representation of Numerical Data by Exponential Curve}

The exponential curve is of the form

$$
\mathrm{y}=\mathrm{a}^{x}
$$

where a \& b are parameters.

Equation (2.1) implies,

$$
\log \mathrm{y}=\log \mathrm{a}+\mathrm{x} \log \mathrm{b}
$$

Since there are two parameters in the exponential curve, two equations are necessary for determining the values of the parameters and accordingly two sets of values the pair of variables are necessary.

Let $y_{0} \& y_{1}$ be the values of y corresponding to the values $x_{0} \& x_{1}$ of x respectively. Then the points

\section{$\left(x_{0}, y_{0}\right) \&\left(x_{1}, y_{1}\right)$}

lie on the equation (2.1) and hence they satisfy (2.2).

Accordingly,

$$
\begin{aligned}
\log y_{0} & =\log \mathrm{a}+{ }^{x_{0}} \log \mathrm{b} \\
\& \quad \log y_{1} & =\log \mathrm{a}+{ }^{x_{1} \log \mathrm{b}}
\end{aligned}
$$

$(2.4)-(2.3) \Rightarrow$

$$
\begin{gathered}
\Delta \log y_{0}=\log \mathrm{b}\left(\Delta x_{0}\right) \\
\Rightarrow \log \mathrm{b}=\left(\frac{\Delta \log y_{0}}{\Delta x_{0}}\right) \text { i.e. } \mathrm{b}=\operatorname{antilog}\left(\frac{\Delta \log y_{0}}{\Delta x_{0}}\right)
\end{gathered}
$$

Now, (2.3) \& (2.4) $\Rightarrow$

$$
\log \mathrm{a}=\log y_{0} x_{0}\left(^{\left.\frac{\Delta \log y_{0}}{\Delta x_{0}}\right)}=\log y_{1}-x_{1}\left(\frac{\Delta \log y_{0}}{\Delta x_{0}}\right)\right.
$$




$$
\text { i.e. } \begin{aligned}
\mathrm{a}=\operatorname{antilog}\left\{\log y_{0}-x_{0}\left(\frac{\Delta \log y_{0}}{\Delta x_{0}}\right)\right\} \\
=\operatorname{antilog}\left\{\log y_{1}-x_{1}\left(\frac{\Delta \log y_{0}}{\Delta x_{0}}\right)\right\}
\end{aligned}
$$

\subsection{Example of Data Representation by Exponential Curve}

The following table shows the data on total population of India corresponding to the years:

Table-2.1.1

\begin{tabular}{|l|l|l|l|}
\hline Year $(\mathrm{t})$ & Total Population $\mathrm{P}(\mathrm{t})$ & Year $(\mathrm{t})$ & Total Population $\mathrm{P}(\mathrm{t})$ \\
\hline 1951 & 361088090 & 1981 & 683329097 \\
\hline 1961 & 439234771 & 1991 & 846302688 \\
\hline 1971 & 548159652 & 2011 & 1210193422 \\
\hline
\end{tabular}

Let us first represent the total populations corresponding to the years $1951 \& 1961$ by the exponential curve described by equation (2.1).

In order to do it let us take the year 1951 as origin (i.e 0) and choose the scale 1/10 such that the value of $\mathrm{x}$ corresponding to the year 1961 becomes 1 . Thus we have the following table:

Table-2.1.2

\begin{tabular}{|l|l|l|l|l|}
\hline $\mathrm{T}$ & $\mathrm{x}$ & $\mathrm{P}(\mathrm{t})$ & $\log \mathrm{P}(\mathrm{t})$ & $\Delta \log \mathrm{P}(\mathrm{t})$ \\
\hline 1951 & 0 & 361088090 & 19.704632503150 & 0.195912110819 \\
1961 & 1 & 439234771 & 19.900544613969 & \\
\hline
\end{tabular}

Now by $(2.5), \quad b=1.21641999047$

Accordingly by (2.6), $\quad \mathrm{a}=361088090$

Therefore, the exponential curve that can represent the total populations corresponding to the years 1951 $\& 1961$

$$
\mathrm{P}(\mathrm{t})=361088090 \times 1.21641999047^{x}=361088090 \times 1.21641999047^{(t-1951) / 10}
$$

This curve yields,

$$
\mathrm{P}(1951)=361088090 \times(1.21641999047)^{0}=361088090
$$


$\& \mathrm{P}(1961)=361088090 \times(1.21641999047)^{1}=439234771$

Thus, the values of $\mathrm{P}(1951) \& \mathrm{P}(1961)$ yielded by the equation of the exponential curve are identical to the corresponding given values of them.

Similarly, the data on total population corresponding to two consecutive years (at a gap of 10 years, 20 years, 30 years etc.) can be represented by the exponential curve. The curves obtained have been shown in the following table (Table-2.1.3).

Table-2.1.3

Exponential curve representing $\mathrm{P}(\mathrm{t})$ total population $\mathrm{P}(\mathrm{t})$ of India

\begin{tabular}{|c|c|}
\hline Years $(\mathrm{t})$ & Equation of the exponential curve representing $\mathrm{P}(\mathrm{t})$ \\
\hline 1951,1961 & $\mathrm{P}(\mathrm{t})=361088090 \times 1.21641999047^{(t-1951) / 10}$ \\
\hline 1961,1971 & $\mathrm{P}(\mathrm{t})=439234771 \times^{1.247987837465^{(t-1961) / 10}}$ \\
\hline 1971,1981 & $\mathrm{P}(\mathrm{t})=548159652 \times^{1.246587731342^{(t-1971) / 10}}$ \\
\hline 1981,1991 & $\mathrm{P}(\mathrm{t})=683329097 \times^{1.238499416627^{(t-1981) / 10}}$ \\
\hline 1991,2001 & $\mathrm{P}(\mathrm{t})=846302688 \times^{1.213531826807^{(t-1991) / 10}}$ \\
\hline 2001,2011 & $\mathrm{P}(\mathrm{t})=1027015247 x^{1.178359742501^{(t-2001) / 10}}$ \\
\hline 1951,1971 & $\mathrm{P}(\mathrm{t})=361088090 \times^{1.518077353367^{(t-1951) / 20}}$ \\
\hline 1961,1981 & $\mathrm{P}(\mathrm{t})=439234771 \times^{1.555726327049^{(t-11961) / 20}}$ \\
\hline 1971,1991 & $\mathrm{P}(\mathrm{t})=548159652 \times^{1.543898178043^{(t-1971) / 20}}$ \\
\hline 1981,2001 & $\mathrm{P}(\mathrm{t})=683329097 \times^{1.502958459560^{(t-1981) / 20}}$ \\
\hline 1991,2011 & $\mathrm{P}(\mathrm{t})=846302688 \times^{1.429977050953^{(t-1991) / 20}}$ \\
\hline 1951,1981 & $\mathrm{P}(\mathrm{t})=361088090 \times 1.892416603937^{(t-1951) / 30}$ \\
\hline 1961,1991 & $\mathrm{P}(\mathrm{t})=439234771 \times^{1.926766148483^{(t-1961) / 30}}$ \\
\hline 1971,2001 & $\mathrm{P}(\mathrm{t})=548159652 \times^{1.873569576405^{(t-1971) / 30}}$ \\
\hline 1981,2011 & $\mathrm{P}(\mathrm{t})=683329097 \times 1.771025743397^{(t-1981) / 30}$ \\
\hline
\end{tabular}


International Journal of Electronics and Applied Research (IJEAR) vol. 4, issue 1, July 2017 Online (http://eses.net.in/ESES Journal)

\begin{tabular}{|l|l|}
\hline 1951,1991 & $\mathrm{P}(\mathrm{t})=361088090 \times \times^{2.343756859993^{(t-1951) / 40}}$ \\
\hline 1961,2001 & $\mathrm{P}(\mathrm{t})=439234771 \times^{2.338192043999^{(t-1961) / 40}}$ \\
\hline 1971,2011 & $\mathrm{P}(\mathrm{t})=548159652 \times^{2.207738963611^{(t-1971) / 40}}$ \\
\hline 1951,2001 & $\mathrm{P}(\mathrm{t})=361088090 \times^{2.844223543900^{(t-1951) / 50}}$ \\
\hline 1961,2011 & $\mathrm{P}(\mathrm{t})=439234771 \times^{2.755231374885^{(t-1961) / 50}}$ \\
\hline 1951,2011 & $\mathrm{P}(\mathrm{t})=361088090 \times^{3.351518522806^{(t-1951) / 60}}$ \\
\hline
\end{tabular}

\section{Representation of Numerical Data by Modified Exponential Curve}

The modified exponential curve is of the form

$$
\mathrm{y}=\mathrm{a}+\mathrm{b}^{c^{x}}
$$

where $\mathrm{a}, \mathrm{b} \& \mathrm{c}$ are parameters.

Let

$y_{0}, y_{1}, y_{2}$

be the values of y corresponding to the values of

$x_{0}, x_{1}, x_{2}$

of $\mathrm{x}$ respectively.

Then the points

$\left(x_{0}, y_{0}\right),\left(x_{1}, y_{1}\right),\left(x_{2}, y_{2}\right)$

lie on the curve described by equation (2.1).

Therefore,

$$
y_{i}=\mathrm{a}+\mathrm{b}^{c^{x_{i}}}, \quad \mathrm{i}=0,1,2
$$

which implies,

$$
\Delta y_{i}=\mathrm{b}\left(c^{x_{i+1}}-c^{x_{i}}\right), \quad \mathrm{i}=0,1
$$

If $x_{0}, x_{1}, x_{2}$ are equally spaced then

$$
x_{1}-x_{0}=x_{2}-x_{1}=\mathrm{h}
$$




$$
\text { i.e. } x_{1}=x_{0+\mathrm{h}} \quad \& \quad x_{2}=x_{0+2 \mathrm{~h}}
$$

Then,

$$
y_{i}=\mathrm{a}+\mathrm{b}^{c^{x_{0}+i h}} \quad, \quad \mathrm{i}=0,1,2
$$

Accordingly,

$$
\Delta y_{0}=\mathrm{b}^{c^{x_{0}}}\left(c^{h}-1\right) \quad \& \Delta y_{1}=\mathrm{b}^{c^{x_{1}}}\left(c^{h}-1\right)
$$

Which implies,

$$
\begin{aligned}
& \frac{\Delta y_{0}}{\Delta x_{0}}=c^{h} \quad \text { i.e. } \log \left(\frac{\Delta y_{0}}{\Delta x_{0}}\right)=h \log c \\
& \text { i.e. } \quad \mathrm{c}=\operatorname{antilog}\left\{\frac{1}{h} \log \left(\frac{\Delta y_{0}}{\Delta x_{0}}\right)\right.
\end{aligned}
$$

From equations in (3.5) expression for $\mathrm{b}$ is obtained as

$$
\mathrm{b}=\frac{\Delta y_{0}}{c^{x_{0}}\left(c^{h}-1\right)}=\frac{\Delta y_{1}}{c^{x_{1}}\left(c^{h}-1\right)}
$$

where $\mathrm{c}$ is given by equation (3.6).

Finally from equations in (3.4), expression for a is obtained as

$$
\mathrm{a}=y_{0}-\mathrm{b}^{c^{x_{0}}}=y_{1}-\mathrm{b}^{c^{x_{1}}}=y_{2}-\mathrm{b}^{c^{x_{2}}}
$$

where b \& c are given by equations (3.7) \& (3.6) respectively.

\subsection{Example of Data Representation by Modified Exponential Curve}

Let us consider the data shown in Table-2.1.1 mentioned in section 2.1.

Let us first represent the total populations corresponding to the years $1951,1961 \& 1971$ by the modified exponential curve described by equation (3.1).

In order to do it let us take, as earlier, the year 1951 as origin (i.e. 0) and choose the scale 1/10 such that the value of $\mathrm{x}$ corresponding to the year 1961 becomes 1 and 1971 becomes 2 . Thus we have the following table (Table-3.1.1). 
Table-3.1.1

\begin{tabular}{|l|l|l|l|l|l|}
\hline $\mathrm{t}$ & $\mathrm{x}$ & $\mathrm{P}(\mathrm{t})$ & $\Delta \mathrm{P}(\mathrm{t})$ & $\frac{\Delta P(t+h)}{\Delta P(t)}$ & $\log \frac{\Delta P(t+h)}{\Delta P(t)}$ \\
1961 & 1 & 439234771 & 108924881 & & \\
1971 & 2 & 548159652 & & & \\
\hline 1951 & 0 & 361088090 & 78146681 & 1.393851659547 & \\
\hline
\end{tabular}

Now by (3.6),

$$
\mathrm{c}=1.3938516595
$$

Accordingly by (3.7),

$\mathrm{b}=198416533.52$

and by (3.8),

$\mathrm{a}=162671556.48$

Therefore, the modified exponential curve that can represent the given data is

$$
\mathrm{P}(\mathrm{t})=162671556.48+198416533.52 \times 1.3938516595^{(t-1951) / 10}
$$

This curve yields,

$$
\begin{aligned}
\mathrm{P}(1951) & =162671556.48+198416533.52=361088090, \\
\mathrm{P}(1961) & =162671556.48+198416533.52 \times 1.3938516595=439234771 \\
\& \mathrm{P}(1971) & =162671556.48+198416533.52 \times 1.39385165952=548159652
\end{aligned}
$$

Similarly, the data on total population corresponding to two consecutive years (at a gap of 30 years) can be represented by the exponential curve. The curves obtained have been shown in the following tables Table-3.1.2. 
Table-3.1.2

Modified exponential curve representing $\mathrm{P}(\mathrm{t})$ total population $\mathrm{P}(\mathrm{t})$ of India

\begin{tabular}{|l|l|}
\hline Years $(\mathrm{t})$ & Equation of the modified exponential curve representing $\mathrm{P}(\mathrm{t})$ \\
\hline $1951,1961,1971$ & $\mathrm{P}(\mathrm{t})=162671556.48+198416533.52 \times(1.3938516595)^{(t-1951) / 10}$ \\
\hline $1961,1971,1981$ & $\mathrm{P}(\mathrm{t})=-12844741.85+452079512.85 \times(1.2409418651)^{(t-1961) / 10}$ \\
\hline $1971,1981,1991$ & $\mathrm{P}(\mathrm{t})=-108964607.87+657124259.87 \times(1.2056984549)^{(t-1971) / 10}$ \\
\hline $1981,1991,2001$ & $\mathrm{P}(\mathrm{t})=-813961579.52+1497290676.52 \times(1.1088456594)^{(t-1981) / 10}$ \\
\hline $1991,2001,2011$ & $\mathrm{P}(\mathrm{t}) \quad-\quad 12398675095.11$ \\
$\times(1.0136438552)^{(t-1991) / 10}$ & + \\
\hline $1951,, 1981,2011$ & $\mathrm{P}(\mathrm{t})=-146377372.04+507467783.11$ \\
\hline
\end{tabular}

\section{Representation of Numerical Data by Pearl \& Reed Curve}

The Pearl \& Reed curve is of the form

$$
\mathrm{y}=\frac{A}{B+C^{x}}
$$

where ${ }^{A}, \mathrm{~B}$ and $\mathrm{C}$ are parameters

As earlier, let

$$
y_{0}, y_{1}, y_{2}
$$

be the values of y corresponding to the values of

$x_{0}, x_{1}, x_{2}$

of $\mathrm{x}$ respectively.

Then the points

$\left(x_{0}, y_{0}\right),\left(x_{1}, y_{1}\right),\left(x_{2}, y_{2}\right)$

lie on the curve described by equation (4.1). 
Therefore,

$$
\begin{aligned}
& y_{i}=\frac{A}{B+c^{x_{i}}} \quad \text { i.e. } \frac{1}{y_{i}}=\frac{B}{A}+\frac{1}{A} c^{x_{\mathrm{i}}} \quad, \quad \mathrm{i}=0,1,2 \\
& \text { This } \Rightarrow \quad \Delta\left(\frac{1}{y_{i}}\right)=\frac{1}{A}\left(c^{x_{\mathrm{i}+1}}-c^{x_{\mathrm{i}}}\right) \quad, \quad \mathrm{i}=0,1
\end{aligned}
$$

If $x_{0}, x_{1}, x_{2}$ are equally spaced then

$$
x_{1}-x_{0}=x_{2}-x_{1}=\mathrm{h} \quad \text { i.e. } \quad x_{1}=x_{0+\mathrm{h}} \quad \& \quad x_{2}=x_{0+2 \mathrm{~h}}
$$

Thus,

$$
\Delta\left(\frac{1}{y_{i}}\right)=\frac{c^{i h}}{A} c^{x_{0}}\left(c^{h}-1\right) \quad, \quad \mathrm{i}=0,1
$$

which implies,

$$
\log \left\{^{\frac{\Delta\left(\frac{1}{y_{1}}\right)}{\Delta\left(\frac{1}{y_{0}}\right)}}\right\}=h \log \mathrm{C}
$$

so that

$$
\begin{aligned}
& \log C=\frac{1}{h} \log \left\{\frac{\Delta\left(\frac{1}{y_{1}}\right)}{\Delta\left(\frac{1}{y_{0}}\right)}\right\} \\
& \text { i.e. } \quad C=\operatorname{antilog}\left[\frac{1}{h} \log \left\{\frac{\Delta\left(\frac{1}{y_{1}}\right)}{\Delta\left(\frac{1}{y_{0}}\right)}\right\}\right.
\end{aligned}
$$

From equations (4.4), expression for A is obtained as

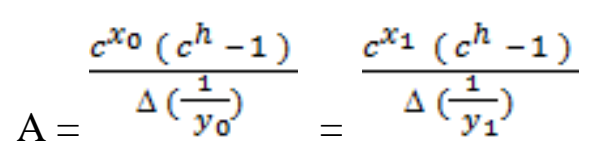

where $\mathrm{C}$ is given by equation (4.6).

Finally from equations (4.3), expression for B is obtained as

$$
\mathrm{B}=\frac{A}{y_{0}}-c^{x_{0}}=\frac{A}{y_{1}}-c^{x_{1}}=\frac{A}{y_{2}}-c^{x_{2}}
$$

where A \& C are given by equations (4.7) \& (4.6) respectively.

\subsection{Example of Data Representation by Pearl \& Reed Curve}


Let us first represent the total populations corresponding to the years $1951,1961 \& 1971$ by the Pearl \& Reed curve described by equation (4.1).

In order to do it let us take, as earlier, the year 1951 as origin (i.e. 0 ) and choose the scale 1/10 such that the value of $\mathrm{x}$ corresponding to the year 1961 becomes 1 and 1971 becomes 2 . Thus we have the following table (Table-4.1.1).

Table-4.1.1

\begin{tabular}{|c|c|c|c|c|c|}
\hline $\mathrm{t}$ & X & $\mathrm{P}(\mathrm{t})=y_{i}$ & $\frac{1}{y_{i}}$ & $\Delta \quad \frac{1}{y_{i}}$ & $\frac{\Delta\left(\frac{1}{y_{i+1}}\right)}{\Delta\left(\frac{1}{y_{i}}\right)}$ \\
\hline 1961 & 1 & $\begin{array}{l}361088090 \\
439234771\end{array}$ & $\begin{array}{l}0.000000002769407321 \\
0.000000002276686788\end{array}$ & $\begin{array}{l}- \\
0.000000000492720533\end{array}$ & 0.9181690619 \\
\hline 1971 & 2 & 548159652 & 0.0000000018242860384 & $\begin{array}{l}- \\
0.0000000004524007496\end{array}$ & \\
\hline
\end{tabular}

Now,

$$
\mathrm{C}=0.9181690619
$$

Accordingly,

$$
\begin{aligned}
\mathrm{A}= & \frac{c^{x_{0}}\left(c^{h}-1\right)}{\Delta\left(\frac{1}{y_{0}}\right)}=\frac{0.9181690619-1}{-0.000000000492720533}=166079821.3578811825 \\
\& \mathrm{~B}= & \frac{A}{y_{0}}-c^{x_{0}}=\frac{166079821.3578811825}{361088090}-1=-0.5400573269
\end{aligned}
$$

Therefore, the Pearl \& Reedcurve that can represent the given data is

$$
\mathrm{y}=\frac{166079821.3578811825}{-0.5400573269+(0.9181690619)^{x}}
$$


i.e. $\quad \mathrm{P}(\mathrm{t})=\frac{166079821.3578811825}{-0.5400573269+0.9181690619^{(t-1951) / 10}}$

This curve yields,

$$
\begin{gathered}
\mathrm{P}(1951)=y_{0}=\frac{A}{B+C^{x_{0}}}=\frac{166079821.3578811825}{-0.5400573269+1} \\
=361088090, \\
\mathrm{P}(1961)=y_{1}=\frac{A}{B+C^{x_{1}}}=\frac{166079821.3578811825}{-0.5400573269+0.9181690619} \\
=439234771 \\
\& \mathrm{P}(1971)=y_{2}=\frac{A}{B+C^{x_{2}}}=\frac{166079821.3578811825}{-0.5400573269+(0.9181690619)^{2}} \\
=548159652
\end{gathered}
$$

These values are identical with the corresponding observed values shown in Table-2.1.1 mentioned in section 2.

The data on total population corresponding to three consecutive years (at a gap of 10 years) can be represented by the Pearl \& Reed curve. The curves obtained have been shown in the following table (Table-4.1.2).

Table-4.1.2

Pearl \& Reed curve representing total population P(t) of India

\begin{tabular}{|l|c|}
\hline Years $(\mathrm{t})$ & Equation of the Pearl \& Reed curve representing $\mathrm{P}(\mathrm{t})$ \\
\hline 1951 & $\mathrm{P}(\mathrm{t})=\frac{166079821.3578811825}{-0.5400573269+0.9181690619^{(t-1951) / 10}}$ \\
1961 & $\mathrm{P}(\mathrm{t})=\frac{4.0182632202+0.7976607733^{(t-1961) / 10}}{1961}$ \\
1981 & \\
\hline 1971 & \\
\hline
\end{tabular}


International Journal of Electronics and Applied Research (IJEAR) vol. 4, issue 1, July 2017 Online (http://eses.net.in/ESES Journal)

\begin{tabular}{|c|c|c|}
\hline $\begin{array}{l}1981 \\
1991\end{array}$ & $\mathrm{P}(\mathrm{t})=$ & $\frac{607034035.4099546391}{0.1074037156+0.7809442825^{(t-1971) / 10}}$ \\
\hline $\begin{array}{l}1981 \\
1991 \\
2001\end{array}$ & $\mathrm{P}(\mathrm{t})=$ & $\frac{930490540.3659358186}{0.36170191551+0.7377753206^{(t-1981) / 10}}$ \\
\hline $\begin{array}{l}1991 \\
2001 \\
2011\end{array}$ & $\mathrm{P}(\mathrm{t})=$ & $\frac{1400316634.9560702305}{0.6546286037+0.7088532327(t-1991) / 10}$ \\
\hline $\begin{array}{l}1951 \\
1981 \\
2011\end{array}$ & $\mathrm{P}(\mathrm{t})=$ & $\frac{392165083.5070385244}{0.0860648533+0.4878388268(t-1951) / 30}$ \\
\hline
\end{tabular}

\section{Representation of Numerical Data by Makeham's Curve}

The Makeham's curve is of the form

$$
\mathrm{y}=\mathrm{a} b^{x} c^{d^{x}}
$$

where a , b , c \& d are parameters.

Let

$y_{0}, y_{1}, y_{2}, y_{3}$

be the values of y corresponding to the values

$x_{0}, x_{1}, x_{2}, x_{3}$

of $\mathrm{x}$ respectively.

Then the points

$\left(x_{0}, y_{0}\right),\left(x_{1}, y_{1}\right),\left(x_{2}, y_{2}\right),\left(x_{3}, y_{3}\right)$

lie on the curve described by equation (1).

Therefore, 


$$
y_{i=\mathrm{a}} b^{x_{i}} c^{d^{x_{i}}} \quad, \quad \mathrm{i}=0,1,2,3
$$

$(5.2) \Rightarrow$

$$
\log y_{i}=\log \mathrm{a}+x_{i} \log \mathrm{b}+d^{x_{i}} \log \mathrm{c} \quad, \quad \mathrm{i}=0,1,2,3
$$

If $x_{0}, x_{1}, x_{2}, x_{3}$ are equally spaced then

$$
x_{1-} x_{0}=x_{2}-x_{1}=x_{3}-x_{2}=\mathrm{h}
$$

i.e. $x_{1}=x_{0+\mathrm{h}}, x_{2}=x_{0+2 \mathrm{~h}} \quad \& \quad x_{3}=x_{0+3 \mathrm{~h}}$

Thus,

$$
\Delta \log y_{i}=\mathrm{h} \log \mathrm{b}+\left(d^{h}-1\right) \log \mathrm{c} d^{x_{i}}, \quad \mathrm{i}=0,1,2
$$

$\& \Delta 2 \log y_{i}=\left(d^{h}-1\right) 2 \log \mathrm{c} d^{x_{i}}, \quad \mathrm{i}=0,1$

Accordingly,

$$
\frac{\Delta^{2} \log y_{1}}{\Delta^{2} \log y_{0}}=d^{h}
$$

Thus,

$\log d=\frac{1}{h} \log \left(\frac{\Delta^{2} \log y_{1}}{\Delta^{2} \log y_{0}}\right)$ i.e. $d=\operatorname{antilog}\left\{\frac{1}{h} \log \left(\frac{\Delta^{2} \log y_{1}}{\Delta^{2} \log y_{0}}\right)\right\}$

Thus d can be Obtained from this equation..

Consequently from (5.5),

$$
\log \mathrm{c}=\frac{\Delta^{2} \log y_{0}}{\left(d^{h}-1\right)^{2} d^{x_{0}}}=\frac{\Delta^{2} \log y_{1}}{\left(d^{h}-1\right)^{2} d^{x_{1}}}
$$

i.e. $\quad \mathrm{c}=\operatorname{antilog}\left\{\frac{\Delta^{2} \log y_{0}}{\left(d^{h}-1\right)^{2} d^{x_{0}}}\right\}=\operatorname{antilog}\left\{\frac{\Delta^{2} \log y_{1}}{\left(d^{h}-1\right)^{2} d^{x_{1}}}\right\}$

Thus c can be obtained from this equation where $\mathrm{d}$ is given by equation (5.7).

Similarly from (5.4),

$$
\log \mathrm{b}=\frac{1}{h}\left\{\Delta \log y_{i}-\left(d^{h}-1\right) \log d^{x_{i}}\right\}, \quad \mathrm{i}=0,1,2
$$

which implies,

$\mathrm{b}=\operatorname{antilog}\left[\frac{1}{h}\left\{\Delta \log y_{i}-\left(d^{h}-1\right) \log \mathrm{c} d^{x_{i}}\right\}\right], \mathrm{i}=0,1,2$ 
Thus $\mathrm{b}$ can be determined from any one of the three equations given in (5.11) where $\mathrm{d} \& \mathrm{c}$ are given by equations (5.7) \& (5.9) respectively.

Similarly from (5.3),

$$
\log \mathrm{a}=\log y_{i}-X_{i} \log \mathrm{b}-\log \mathrm{c}, \quad \mathrm{i}=0,1,2,3
$$

which implies,

$$
\mathrm{a}=\operatorname{antilog}\left\{\log y_{i}-x_{i} \log \mathrm{b}-\log \mathrm{c}\right\} \quad, \quad \mathrm{i}=0,1,2,3
$$

Thus a can be determined from any one of the four equations given in (5.13) where $\mathrm{d}, \mathrm{c} \& \mathrm{~b}$ are given by equations (5.7), (5.9) \& (5.11) respectively.

\subsection{Example of Data Representation by Makeham's Curve}

Let us represent the data on total populations of India corresponding to the years $1951,1961,1971 \&$ 1981 (shown in Table-2.1.1 mentioned in section 2.1) by the modified exponential curve described by equation (5.1).

As earlier, in order to do it let us take the year 1951 as origin (i.e. 0 ) and choose the scale 1/10 such that the values of $x$ corresponding to the years 1961, 1971 \& 1981 become 1, 2 \& 3 respectively. Now, let us construct the following table (Table-5.1.1) :

Table-5.1.1

\begin{tabular}{|l|l|l|l|l|l|}
\hline $\mathrm{T}$ & $\mathrm{x}$ & $\mathrm{P}(\mathrm{t})$ & $\log \mathrm{P}(\mathrm{t})$ & $\Delta \log \mathrm{P}(\mathrm{t})$ & $\Delta^{2} \log \mathrm{P}(\mathrm{t})$ \\
\hline 1951 & 0 & 361088090 & 19.704632503150 & 0.195912110819 & 0.02562041346 \\
1961 & 1 & 439234771 & 19.900544613969 & 0.221532524279 & -00112252063 \\
1971 & 2 & 548159652 & 20.122077138248 & 0.220410003649 & \\
1981 & 3 & 683329097 & 20.342487141897 & & \\
\hline
\end{tabular}

Now by (5.7),

$$
\mathrm{d}=-0.043813525170
$$

By (5.9),

$$
c=1.023793397619
$$


By (5.11),

$$
b=1.246646468467
$$

By (5.12),

$$
a=352696247.934125408029
$$

Thus the Makeham's curve satisfying the data is

$$
\mathrm{P}(\mathrm{t})=\mathrm{a}^{(t-1951) / 10} c^{d^{(t-1951) / 10}}
$$

with the above values of $a, b, c \& d$.

This curve yields,

$$
\begin{aligned}
\mathrm{P}(1951)= & 352696247.934125408029 \times 1.023793397619 \\
\mathrm{P}(1961)= & 352696247.934125408029 \times 1.246646468467 \times \\
(1.023793397619)^{-0.043813525170} & \\
= & 439234771 \\
\mathrm{P}(1971)= & 352696247.934125408029 \times(1.246646468467)^{2} \times \\
& (1.023793397619)^{(-0.043813525170)^{2}} \\
= & 548159652 \\
\& \mathrm{P}(1981)= & 352696247.934125408029 \times(1.246646468467)^{3} \times \\
& (1.023793397619)^{(-0.043813525170)^{\mathrm{g}}} \\
= & 683329097
\end{aligned}
$$

\section{Conclusion}

The exponential curve contains two parameters. Accordingly, when two pairs of numerical data are available, they can be represented by exponential curve. However, when two pairs of numerical data are available then they can be represented by linear curve also since the linear curve also contains two parameters. Thus, one question arises -- which of the two curves will suit a set of numerical data better. The exponential curve described by equation (2.1) satisfies the property that,

$$
\Delta\left(\log y_{x}\right)=\text { constant }
$$

On the other hand, the linear curve described by equation (2.7) satisfies the property that 


$$
\Delta y_{x}=\text { constant }
$$

Thus, comparing the values of $\Delta y_{x}$ and $\Delta\left(\log y_{x}\right)$ one can determine which of the two curves will suit a set of numerical data better.

The method of representing numerical data on a pair of variables by modified exponential curve described by equation (3.1) is applicable in representing a set of numerical data on a pair of variables if the given values of the independent variable are equidistant. In the case where the given values of the independent variable are equidistant, the method fails to represent the given data by modified exponential curve. The modified exponential curve contains three parameters. Accordingly, when three pairs of numerical data are available, they can be represented by modified exponential curve. However, when three pairs of numerical data are available then they can be represented by quadratic curve also since quadratic curve also contains three parameters. Thus, one question arises -- which of the two curves will suit the entire data better.

The quadratic curve is of the form

$$
y=\alpha x+\beta x+\gamma
$$

where $^{\alpha}, \beta, \gamma$ are the parameters of the curve

and it satisfies the property that

$\Delta^{2} y_{i}=$ constant

On the other hand, the modified exponential curve described by equation (3.1) satisfies the property that

$\underline{\Delta y_{i+1}}$

$\Delta y_{i}=$ constant

Thus, comparing the values of

$\Delta^{2} y_{i} \& \frac{\Delta y_{i+1}}{\Delta y_{i}}$

one can determine which of the two curves will suit a set of numerical data better.

Similarly, the method of representing numerical data on a pair of variables by Pearl \& Reed curve described by equation (4.1) is applicable in representing a set of numerical data on a pair of variables if the given values of the independent variable are equidistant. In the case where the given values of the independent variable are not equidistant, the method fails to represent the given data by logistic curve. 
The Pearl \& Reed curve contains three parameters. Accordingly, when three pairs of numerical data are available, they can be represented by logistic curve. However, when three pairs of numerical data are available then they can also be represented by quadratic curve and by modified exponential curve since each of these two curves also contains three parameters. As earlier, in this case also one question ariseswhich of the three curves will suit a set of numerical data best among the three ones.

The quadratic curve is of the form

$$
y=\alpha x+\beta x+\gamma
$$

where ${ }^{\alpha}, \beta, \gamma$ are the parameters of the curve and it satisfies the property that

$$
\Delta^{2} y_{i}=\text { constant }
$$

On the other hand, the modified exponential curve described by the equation

$$
\mathrm{y}=\mathrm{a}+\mathrm{b}^{c^{x}}
$$

where a, b \& c are parameters; satisfies the property that

$$
\frac{\Delta y_{i+1}}{\Delta y_{i}}=\text { constant }
$$

Again, the Pearl \& Reed curve described by the equation (4.1) satisfies the property that

$$
\frac{\Delta\left(\frac{1}{y_{1}}\right)}{\Delta\left(\frac{1}{y_{0}}\right)}=\text { constant }
$$

Thus, comparing the values of

$$
\Delta^{2} y_{i}, \frac{\Delta y_{i+1}}{\Delta y_{i}} \& \frac{\Delta\left(\frac{1}{y_{1}}\right)}{\Delta\left(\frac{1}{y_{0}}\right)}
$$

one can determine which of the three curves will suit the entire data best among the three ones.

Again, the method of representing numerical data on a pair of variables by Makeham's curve described by equation (5.1) is applicable in representing a set of numerical data on a pair of variables if the given values of the independent variable are equidistant. In the case where the given values of the independent variable are equidistant, the method fails to represent the given data by modified exponential curve. The Makeham's curve contains four parameters. Accordingly, when four pairs of numerical data are available, they can be represented by Makeham's curve. However, when four pairs of numerical data are available 
then they can be represented by a cubic curve also since cubic curve also contains four parameters. Thus in this case also, one question arises -- which of the two curves will suit a set of numerical data better.

The cubic curve is of the form

$$
\mathrm{y}=\alpha \times 3+\beta \mathrm{x} 2+\gamma \mathrm{x}+\delta
$$

where ${ }^{\alpha}, \beta, \gamma, \delta$ are the parameters of the curve

and it satisfies the property that

$\Delta^{3} y_{i}=$ constant

On the other hand, the modified exponential curve described by equation (3.1) satisfies the property that

$$
\frac{\Delta^{2} \log y_{i+1}}{\Delta^{2} \log y_{i}}=\text { constant }
$$

Thus, comparing the values of

$$
\Delta^{3} y_{i} \& \frac{\Delta^{2} \log y_{i+1}}{\Delta^{2} \log y_{i}}
$$

one can determine which of the two curves will suit a set of numerical data better. 


\section{References}

Abramowitz M., "Handbook of Mathematical Functions with Formulas, Graphs, and Mathematical Tables", 9th printing, New York: Dover, 880, 1972.

Abramowitz M \& Stegun I. A., "Exponential Function", Handbook of Mathematical Functions with Formulas, Graphs, and Mathematical Tables, 9th printing, New York: Dover, 69-71, 1972.

Annadurai G., Rajesh Babu S. \& Srinivasamoorthy V. R., "Development of mathematical models (Logistic, Gompertz and Richards models) describing the growth pattern of Pseudomonas putida (NICM 2174)", Bioprocess Engineering, Vol. 23, 607-612, 1999.

Bathe K. J. \& Wilson E. L., "Numerical Methods in Finite Element Analysis", Prentice-Hall, Englewood Cliffs, NJ, 1976.

Beyer W. H., “CRC Standard Mathematical Tables, 28th ed.” Boca Raton, FL: CRC Press, pp. 217, 1987.

Borwein J., Bailey D. \& Girgensohn R., "Experimentation in Mathematics: Computational Paths to Discovery". Wellesley, MA: A K Peters, 2004.

Chakrabarty Dhritikesh, "Representation of Numerical Data on a Pair of Variables by a Polynomial Curve Expressed in the Simplest Form", International Journal of Electronics and Applied Research, Vol. 3, No. 1, 26 39, $2016 \mathrm{a}$.

Chakrabarty Dhritikesh, "Interpolation: One Method of Representation of Numerical Data on a Pair of Variables by a Polynomial Curve Expressed In the Simplest Form", Journal of Environmental Science, Computer Science and Engineering \& Technology, Section C, Vol. 5, No. 3, 405 - 418, $2016 \mathrm{~b}$.

Chakrabarty Dhritikesh, "Difference and Ratio Operators: Representation of Numerical Data on a Pair of Variables by a Polynomial Curve”, Journal of Environmental Science, Computer Science and engineering \& Technology, Section C, Vol. 5, No. 4, 549-560, 2016c.

Chakrabarty Dhritikesh, "Recent Developments on Representation of Numerical Data by a Polynomial Curve", International Journal of Electronics and Applied Research, Vol. 3, No. 2, 125 - 158, 2016d.

Chakrabarty Dhritikesh, "Backward Difference and Ratio Operations: Representation of Numerical Data on a Pair of Variables by a Polynomial Curve", Journal of Environmental Science, Computer Science and Engineering \& Technology, Section C, Vol. 6, No. 1,027 -039, 2016 - 17, Also available in www.jecet.org .

Chakrabarty Dhritikesh, "Some Forms of Interpolation Formula Based on Divided Difference", Journal of Environmental Science, Computer Science and Engineering \& Technology, Section C, Vol. 6, No. 2, 199 - 211, 2017, Also available in www.jecet.org .

Cayley A., "A Memoir on the Theory of Matrices". Phil.Trans., Vol. 148, 1858.

Cayley A., "The Collected Mathematical Papers of Arthur Cayley (Classic Reprint)", Forgotten books, ASIN B008HUED9O, 1889.

Chapra S. C. \& Canale R. P. , "Numerical Methods for Engineers”, third ed., McGraw-Hill, NewYork, 2002. 
Chwaiger J.,"On a Characterization of Polynomials by Divided Differences”, Aequationes Math, Vol. 48, 317 323, 1994.

Conte S. D. \& Boor Carl de, “Elementary Numerical Analysis”, 3 Ed, McGraw-Hill, New York, USA, 1980.

Corliss J. J., "Note on an Extension of Lagrange's Formula", American Mathematical Monthly Jstor, Vol. 45, No. 2, $106-107,1938$.

Das Biswajit \& Chakrabarty Dhritikesh, "Lagranges Interpolation Formula: Representation of Numerical Data by a Polynomial Curve", International Journal of Mathematics Trend and Technology Vol. 34 (part-1), No. 2, 23 - 31, $2016 \mathrm{a}$.

Das Biswajit \& Chakrabarty Dhritikesh, "Newton's Divided Difference Interpolation Formula: Representation of Numerical Data by a Polynomial Curve", International Journal of Mathematics Trend and Technology, Vol. 35 (part-1), No. 3, 26-32, 2016b.

Das Biswajit \& Chakrabarty Dhritikesh, "Newton's Forward Interpolation Formula: Representation of Numerical Data by a Polynomial Curve", International Journal of Applied Research, Vol. 1, No. 2, 36 - 41, 2016c.

Das Biswajit \& Chakrabarty Dhritikesh, "Newton's Backward Interpolation Formula: Representation of Numerical Data by a Polynomial Curve", International Journal of Statistics and Applied Mathematics, Vol.2, No. 10,513 $517,2016 \mathrm{~d}$.

Das Biswajit \& Chakrabarty Dhritikesh, "Matrix Inversion: Representation of Numerical Data by a Polynomial curve", Aryabhatta Journal of Mathematics \& Informatics, Vol. 8, No. 2, pp. 267 - 276, 2016e.

Das Biswajit \& Chakrabarty Dhritikesh, "Inversion of Matrix by Elementary Transformation: Representation of Numerical Data by a Polynomial Curve", Journal of Mathematis and System Sciences, Vol. 12, No., 27 - 32, $2016 \mathrm{f}$.

Das Biswajit \& Chakrabarty Dhritikesh, "Inversion of Matrix by Elementary Column Transformation: Representation of Numerical Data by a Polynomial Curve", International Journal of Mathematics Trends and Technology, Vol. 42, No. 1, 45 -49, 2017a, Also available in http://www.ijmttjournal.org .

Das Biswajit \& Chakrabarty Dhritikesh, "Backward Divided Difference: Representation of Numerical Data by a Polynomial Curve", International Journal of Statistics and Applied Mathematics, Vol. 2, No. 2, 1 - 6, 2017b, Also available in http://www.mathsjournal.com .

De Boor C., "A divided difference expansion of a divided difference", J. Approx. Theory, Vol. 122, 10 - 12, 2003.

Dokken T. \& Lyche T., "A divided difference formula for the error in Hermite interpolation”, BIT, Vol. 19, 540 $541,1979$.

Erdos P. \& Turan P., "On Interpolation II: On the Distribution of the Fundamental Points of Lagrange and Hermite Interpolation”, The Annals of Mathematics, 2nd Ser", Jstor, Vol. 39, No. 4, 703 - 724, 1938.

Echols W. H., "On Some Forms of Lagrange's Interpolation Formula", "The Annals of Mathematics, Jstor, Vol. 8, No. 1, 22 - 24, 1893. 
Endre S. \& David M. , “An Introduction to Numerical Analysis”, Cambridge, UK, 2003.

Floater M. , "Error formulas for divided difference expansions and numerical differentiation", J. Approx. Theory, Vol. 122, 1-9, 2003.

Fred T., "Recurrence Relations for Computing with Modified Divided Differences", Mathematics of Computation, Vol. 33, No. 148, 1265 - 1271, 1979.

Gertrude B. , "On Modified Divided Differences", Mathematical Tables and Other Aids to Computation, Vol. 8, No. 45, $1-11,1954$.

Gerald C. F. \& Wheatley P.O., “Applied Numerical Analysis”, fifth ed., Addison-Wesley Pub. Co., MA, 1994.

Gershenfeld Neil A. “The Nature of Mathematical Modeling”,Cambridge, UK: Cambridge University Press, 1999.

Herbert E. S., "Multi-Point Generalization of Newton's Divided Difference Formula", Proceedings of the American Mathematical Society, Jstor, Vol. 13, No. 2, 210 - 212, 1962.

Hummel P. M., “A Note on Interpolation (in Mathematical Notes)”, American Mathematical Monthly, Jstor, Vol. 54, No. 4, $218-219,1947$.

Hamilton W. R., “Lectures on Quaternions”, Dublin , 1853.

Hamilton W. R., "On the Existence of a Symbolic and Biquadratic Equation which is satisfied by the Symbol of Linear or Distributive Operation on a Quaternion", The London, Edinburgh and Dublin Philosophical Magazine and Journal of Science, Series IV, Taylor \& Francis 24, 127 - 128, 1862.

Hamilton W. R., "On a New and General Method of Inverting a Linear and Quaternion Function of a Quaternion", Proceedings of the Royal Irish Academy, Royal Irish Academy, Vol. 8, 182 - 183, 1864a.

Hamilton W. R. , "On the Existence of a Symbolic and Biquadratic Equation, which is satisfied by the Symbol of Linear Operation in Quaternions", Proceedings of the Royal Irish Academy, Royal Irish Academy, Vol. 8, 190-101, $1864 b$.

Jannedy Stefanie, Bod Rens \& Hay Jennifer., “Probabilistic Linguistics”, Cambridge, Massachusetts: MIT Press, 2003.

Jan K. W., "Note on Interpolation (in Notes)", Journal of the American Statistical Association, Jstor, Vol. 25, 170, $203-205,1930$.

Jeffreys H. \& Jeffreys B. S., "Divided Differences”, Methods of Mathematical Physics, 3rd ed, 260 - 264, 1988.

John H. M. \& Kurtis D.F. , “Numerical methods using MATLAB”, 4ed, Pearson Education, USA, 2004.

Jordan C., "Calculus of Finite Differences”, 3rd ed, New York, Chelsea, 1965.

Kendall E. Atkinson, “An Introduction to Numerical Analysis”, 2nd Ed., New York, 1989. 
Kincard David R. \& Ward Chaney E., "Numerical analysis”, Brooks /Cole, Pacific Grove, CA, 1991.

Kingsland Sharon E. "Modeling nature: episodes in the history of population ecology". Chicago: University of Chicago Press, 1995.

Krantz S. G., "The Exponential and Applications.", Handbook of Complex Variables. Boston, MA: Birkhäuser, pp. 7-12, 1999.

Lee E. T. Y. , “A Remark on Divided Differences”, American Mathematical Monthly, Vol. 96, No 7, 618 - 622, 1989.

Mills T. M. , “An introduction to analysis by Lagrange interpolation”, Austral. Math. Soc. Gaz., MathSciNet, Vol. 4, No. 1, $10-18,1977$.

Makeham W. M., "On the Law of Mortality and the Construction of Annuity Tables." J. Inst. Actuaries and Assur. Mag., Vol. 8, 301-310, 1860.

Makeham W. M., "On an Application of the Theory of the Composition of Decremental Forces." J. Inst. Actuaries and Assur. Mag., Vol. 18, 317-322, 1874.

Nasrin Akter Ripa, "Analysis of Newton's Forward Interpolation Formula”, International Journal of Computer Science \& Emerging Technologies, Vol. 1, No. 4, 2010.

Neale E. P. \& Sommerville D. M. Y., "A Shortened Interpolation Formula for Certain Types of Data", Journal of the American Statistical Association, Jstor, Vol. 19, No. 148, 515 - 517, 1924.

Quadling D. A. , "Lagrange's Interpolation Formula”, The Mathematical Gazette, Vol. L, No. 374, pp. 372 - 375, 1966.

Robert J. Schilling \& Sandra L. Harries, "Applied Numerical Methods for Engineers", Brooks /Cole, Pacific Grove, $C A, 2000$.

Revers \& Michael Bull, "On Lagrange interpolation with equally spaced nodes", Austral. Math. Soc, MathSciNet., Vol. 62, No. 3, $357-368,2000$.

Scarborough James B., "Numerical Mathematical Analysis”, 6 Ed, The John Hopkins Press, USA, 1996.

Traub J. F., "On Lagrange-Hermite Interpolation", Journal of the Society for Industrial and Applied Mathematics, Jstor, Vol. 12, No. 4, 886 - 891, 1964.

Vertesi P., "SIAM Journal on Numerical Analysis”, Jstor, Vol. 27, No. 5, 1322-1331, 1990.

Whittaker E. T. and Robinson G., "The Gregory-Newton Formula of Interpolation" and "An Alternative Form of the Gregory-Newton Formula", The Calculus of Observations: A Treatise on Numerical Mathematics, 4th ed, 10 $15,1967 \mathrm{a}$.

Whittaker E. T. \& Robinson G., "Divided Differences \& Theorems on Divided Differences", The Calculus of Observations: A Treatise on Numerical Mathematics, 4th ed., New York, 20 - 24, 1967b. 